\title{
MENSURANDO A DEMOCRACIA NOS GOVERNOS ESTADUAIS: UMA PROPOSTA PARA CONSTRUÇÃO DO ÍNDICE DE CAPACIDADE INSTITUCIONAL DOS CONSELHOS DE POLÍTICAS PÚBLICAS (ICI) ${ }^{1}$
}

\author{
André Luiz. Nogueira da Silva ${ }^{2}$ \\ Damião Ernane de Souza ${ }^{3}$
}

\begin{abstract}
Resumo
A tarefa de mensurar/avaliar a democracia no Brasil ainda é um desafio para as ciências sociais. A opção brasileira por um modelo democrático participativo indica a necessidade de investigação sobre a efetividade das instituições que o compõem. Instituídos com o objetivo de democratizar o processo decisório, os Conselhos de políticas públicas serviriam para facilitar a captação das demandas da população local e para incluí-la no planejamento, implementação e avaliação das ações governamentais. Este artigo objetiva propor um índice que permita medir a capacidade institucional dos Conselhos estaduais em influenciar as políticas públicas. O Índice de Capacidade Institucional dos Conselhos (ICI) foi construído com base nas características colocadas pela literatura como essenciais para o funcionamento destes fóruns participativos. Os dados utilizados na sua composição foram extraídos da Pesquisa de Informações Básicas Estaduais 2012 do IBGE. Os resultados apontam para uma heterogeneidade no nível de capacidade institucional dos conselhos, observada nas regiões e por área de políticas pública. Argumenta-se que o funcionamento parcial dos conselhos de políticas públicas ainda constitui-se num empecilho para a democratização do processo decisório no âmbito estadual. Devido ao seu protagonismo coordenativo e sua potencialidade indutora, a União tem um papel fundamental para aprimorar estes canais de participação popular. Prova disso é a alta capacidade institucional de conselhos de áreas com intensa influência do ente federal, como saúde, educação e assistência social - organizadas a partir de sistemas nacionais de políticas públicas. Tal proposição sugere uma reduzida propensão dos gestores estaduais em democratizar o processo decisório em áreas pouco reguladas pelo governo central. Aponta, ademais, para a necessidade dos estudos sobre instituições participativas incluírem o desenho institucional da sua área de atuação como variável relevante para a mensuração de sua efetividade.
\end{abstract}

Palavras-chave: democracia participativa; conselhos estaduais de políticas públicas; capacidade institucional.

\footnotetext{
Abstract

The task of measuring / evaluating the brazilian democracy is still a challenge for the Social Sciences. The brazilian choice for a participatory democratic model indicates the need for research on the effectiveness of the institutions that comprise it. Instituted with aim to democratize the decisionmaking process, the Councils of public policies serve to facilitate the capture of the demands of local people and to include them in the planning, implementation and evaluation of government actions. This article aims to propose an index to measure the institutional capacity of state councils in influencing public policy. The Institutional Capacity Index of Councils (ICI) was constructed based on the characteristics posed by the literature as essential to the functioning of these participatory forums. The data used in its composition were obtained from the Pesquisa de Informações Básicas Estaduais 2012 do IBGE. The results point to a heterogeneity in the level of institutional capacity of the councils, observed in the regions and by area of public policies. It is argued that the partial functioning of the councils of public policy still constitutes a limit to the democratization of the decision-making process at the state level. Due to its coordinative role and its inducing potential, the

${ }^{1}$ DOI deste artigo: $10.5380 /$ recp.v6i1.37486.

${ }^{2}$ Mestre em Estudos Urbanos e Regionais pela UFRN e Analista de Planejamento, Gestão e Infraestrutura do IBGE/RN.

3 Doutor em Saúde Pública pelo ISC/UFBA e Analista de Gestão em Pesquisa do IBGE/RN
} 
Union has a basic task to improve these channels of popular participation. Proof of this is the high institutional capacity of councils in areas with intense influence of the federal government such as health, education and social assistance - arranged from national systems of public policies. This proposition suggests a reduced propensity of state authorities to democratize the decision-making process in areas little regulated by the central government. Points, furthermore, to the need for studies on participatory institutions include the institutional design of their area of expertise as a relevant variable for measuring its effectiveness.

Keywords: participatory democracy; state councils of public policies; institutional capacity.

\section{Resumen}

La tarea de medición / evaluación de la democracia brasileña sigue siendo un reto para las Ciencias Sociales. La selección brasileña para un modelo democrático participativo indica la necesidad de una investigación sobre la eficacia de las instituciones que lo conforman. Instituido con el objetivo de democratizar el proceso de toma de decisiones, los Consejos de las políticas públicas sirven para facilitar la captura de las demandas de la población local y para incluirlos en la planificación, implementación y evaluación de las acciones del gobierno. Este artículo tiene como objetivo proponer un índice para medir la capacidad institucional de los consejos estatales para influir en las políticas públicas. El Índice de Capacidad Institucional de Consejos (ICI) se construyó sobre la base de las características que plantea la literatura como esencial para el funcionamiento de estos foros participativos. Los datos utilizados en su composición se obtuvieron de la Pesquisa de Informações Básicas Estaduais 2012 del IBGE. Los resultados apuntan a una heterogeneidad en el nivel de la capacidad institucional de los consejos, se observan por las regiones y por el ámbito de las políticas públicas. Se argumenta que el funcionamiento parcial de los consejos de política pública todavía constituye un límite a la democratización del proceso de toma de decisiones a nivel estatal. Debido a su papel de coordinación y su potencial de inducir, la Unión tiene una tarea básica para mejorar estos canales de participación popular. Prueba de ello es la alta capacidad institucional de los consejos en zonas con intensa influencia del gobierno federal, como la salud, la educación y la asistencia social dispuesto de los sistemas nacionales de las políticas públicas. Esta proposición sugiere una propensión reducida de los gobernadores para democratizar el proceso de toma de decisiones en áreas poco regulados por el gobierno central. Señala, además, a la necesidad de estudios sobre las instituciones participativas incluyen el diseño institucional de su área de especialización como una variable relevante para medir su eficacia.

Palabras Clave: la democracia participativa; consejos estatales de las políticas públicas; la capacidad institucional.

\section{INTRODUÇÃO}

A tarefa de mensurar/avaliar a democracia no Brasil ainda é um desafio para as ciências sociais. A opção brasileira por um modelo democrático participativo indica a necessidade de investigação sobre a efetividade das instituições que o compõem. Desta feita, os Conselhos de políticas públicas, por seu "ineditismo, magnitude e longevidade" (CÔRTES, 2007) e seu potencial democratizante, surgem como locus principal para avaliação do regime político adotado pelo país em 1988. Ademais, sua criação e disseminação pelos governos subnacionais fortalece a importância destes fóruns participativos no sistema político nacional, caracterizado por uma gama de atribuições compartilhadas entre todos os entes federados. 
Instituídos com o objetivo de democratizar o processo decisório, os Conselhos de políticas públicas serviriam para facilitar a captação das demandas da população local e para incluí-la no planejamento, implementação e avaliação das ações governamentais. A ideia era que os Conselhos pudessem influenciar as políticas públicas. Como as decisões estatais partiriam de uma deliberação pública, elas possuiriam maior legitimidade e maior capacidade de promover mudanças sociais (GOHN, 2004). Neste sentido, analisar a capacidade institucional dos Conselhos na efetivação de sua função política parece ser um dos caminhos para compreensão da democracia brasileira.

Estudar a efetividade das instituições participativas brasileiras não é tarefa inédita, tão pouco recente. Ao longo da década de 1990, inúmeras pesquisas se valeram das premissas teórico-normativas da democracia participativa para desvendar a nova realidade do sistema político do país. Nos últimos anos, os estudos têm desvalorizado a mera existência de canais decisórios alternativos como qualificador da democracia, passando a se preocupar com os resultados das decisões tomadas no âmbito das instituições participativas. Tendo como base a teoria deliberativa, as análises passaram incorporaram a ideia de que a qualidade das decisões seria mais importante do que o simples resultado do processo de agregação de interesses.

Avritzer (2011) coloca que as novas pesquisas em geral focam em dois aspectos da deliberação: (1) a discussão e deliberação no interior das instituições participativas e (2) o efeito desta participação na implementação das decisões estatais. A discussão aqui empreendida tangencia os dois fatores a medida que aborda as características e a estrutura de funcionamento dos Conselhos de política públicas. A ideia é propor um índice que permita mensurar a capacidade institucional dos Conselhos estaduais em influenciar as políticas públicas. O Índice de Capacidade Institucional dos Conselhos (ICI) foi construído com base nas características colocadas pela literatura como essenciais para o funcionamento destas instituições. Os dados utilizados na sua composição foram extraídos da Pesquisa de Informações Básicas Estaduais 2012 (ESTADIC) da Fundação Instituto Brasileiro de Geografia e Estatística (IBGE).

A construção de um índice sintético permite a visualização de um panorama geral sobre os conselhos estaduais no Brasil e em determinadas áreas de atuação governamental. No caso deste trabalho, optou-se por estudar os conselhos estaduais de 09 (nove) setores postos pela Constituição de 1988 como de atuação compartilhada entre os três níveis de 
governos, a saber: educação, cultura, esporte, habitação, transporte, saúde, segurança pública, meio ambiente e assistência social. $\mathrm{O}$ índice, ademais, tem o potencial de apontar a posição dos governos estaduais quanto a incorporação destas instituições participativas às suas gestões. Pressupõe-se, além disso, que a construção e divulgação de indicadores institucionais são essenciais tanto para formulação e avaliação de políticas de indução do governo central quanto para o controle social das ações governamentais (JANUZZI, 2012).

O artigo, inicialmente, aborda o papel que os Conselhos de políticas públicas assumiram no Brasil após a Constituição de 1988, resgatando os principais problemas que afetam o seu pleno funcionamento. Posteriormente, apresenta a metodologia para construção do ICI, definindo as variáveis que o compõem. Em seguida, analisa os resultados encontrados para os Conselhos estaduais no âmbito do país e das regiões, bem como por área de política pública. Encerra-se o estudo com algumas proposições conclusivas.

\section{A DEMOCRACIA BRASILEIRA PÓS-1988 E OS CONSELHOS DE POLÍTICAS PÚBLICAS}

Desde o fim da Ditadura Militar, o sistema político brasileiro vem passando por profundas modificações. Com a promulgação da Constituição de 1988, novas instituições foram sendo criadas com vistas a desenhar um novo modelo de democracia para o país. Resultado de intenso debate e mobilização social, o novo ordenamento constitucional passou a exigir a participação da sociedade civil na gestão de políticas públicas das mais diversas áreas.

Tal condição orientou a democracia brasileira para um caminho que ultrapassa os limites da perspectiva representativa. Ou seja, a existência de eleições diretas, livres e periódicas não era mais suficiente. Buscava-se um arranjo democrático mais participativo, pois se acreditava no seu potencial reformador; na sua capacidade de inverter as prioridades, diminuindo as iniquidades sociais (GOHN, 2004; DAGNINO, 2002). A premissa era que a ampliação da participação pressionaria o Estado, ampliando a transparência e o controle de suas ações. Ademais, a participação geraria um impacto direto nos participantes, agindo como fator educacional na promoção da cidadania (TATAGIBA, 2002). 
Com este sentimento, a gestão pública brasileira passou a inovar, criando mecanismos que favorecessem a participação social na elaboração, implementação e avaliação das ações governamentais. As experiências com Orçamento Participativo Municipal, a realização de Conferências temáticas e a criação de Conselhos de Políticas Públicas são exemplos destas inovações, que aos poucos vem configurando o desenho democrático do país. Desse modo, os estudos que venham a se debruçar sobre a democracia brasileira devem focar seus esforços na análise destes novos fóruns participativos. Isto porque, a compreensão da democracia de um país passa pela compreensão das instituições que a constituem (DAHL, 2012).

Este cenário participativo tem gerado inúmeros estudos que tratam não apenas da incidência e diversidade de formas de participação pelo território nacional, mas também da questão da efetividade destas institucionalidades. Além da influência da literatura internacional, a tentativa de associar as instituições participativas com a implementação de políticas públicas específicas está na raiz do interesse dos pesquisadores da democracia nacional. Para Avritzer (2011), um dos principais problemas destas pesquisas está na diversidade de aportes teóricos que são utilizados, o que acaba por dificultar a realização dos estudos comparativos. Como exemplo, alguns estudos identificam elementos deliberativos nos fóruns participativos brasileiros (CUNHA, 2007), enquanto outros questionaram tal similaridade com o modelo proposto pela teoria deliberativa (SILVA e SOUZA, 2013).

Vaz (2011) divide os estudos sobre a democracia participativa no Brasil em duas fases. A primeira, presente ao longo da década de 1990, partiu da premissa de que a expansão das instituições participativas por si só implicaria no aprofundamento democrático. Tendo como principal instrumental teórico as ideias de Carole Pateman (1992), os trabalhos partiam da premissa de que as novas instituições possibilitariam um aprendizado político, instituindo uma nova configuração na relação entre Estado e cidadãos. Estes novos fóruns representariam uma possibilidade de participação de grupos historicamente marginalizados do processo decisório, podendo servir, assim, como centro de redistribuição de recursos públicos.

O segundo momento das pesquisas sobre os espaços participativos, iniciada no final da década de 1990 e presente até os dias atuais, passou a incorporar novas preocupações que extrapolavam a teoria normativa proposta pela democracia participativa. $\mathrm{O}$ interesse passou a ser a qualidade das decisões coletivas produzidas no interior dos fóruns participativos. $\mathrm{O}$ foco recaiu sobre a identificação de fatores que explicassem a variação de resultados nas 
instituições participativas. Para Vaz, "A emergência da segunda fase de estudos torna clara a preocupação de pesquisadores com variáveis capazes de influenciar, condicionar e mesmo determinar o funcionamento e a consolidação dessas instituições” (2011, p. 96). A teoria deliberativa ganhou ênfase, substituindo a apologia sobre a participação direta pela importância de constituição de espaços decisórios alternativos e sobre a qualificação destas decisões.

A rápida disseminação nas três esferas de governo e nas diversas áreas de atuação estatal ${ }^{4}$ e o potencial de promover o debate de ideias antagônicas sobre determinados temas, fizeram dos Conselhos de Políticas Pública importante objeto das pesquisas sobre instituições participativas. Para Cunha et al, "[os Conselhos] oferecem características centrais do processo deliberativo, o que possibilita que a participação dos diferentes atores nesses espaços seja analisada a partir da lente da teoria deliberativa" (2011, p. 304).

A criação destes espaços ocorreu muito em virtude da "indução promovida por processos de descentralização que condicionavam a transferência de recursos financeiros federais para os níveis subnacionais de governo" (CÔRTES, 2007, p. 137). Ou seja, a expansão destes fóruns acompanhou os processos de descentralização por que passaram algumas políticas sociais nas duas últimas décadas 5 .

Novo componente do arcabouço administrativo do país, os Conselhos tinham a função de democratizar a tomada de decisão e de facilitar a captação das demandas da população. Tratam-se de "espaços públicos de composição plural e paritária entre Estado e sociedade civil, de natureza deliberativa, cuja função é formular e controlar a execução das políticas públicas setoriais" (TATAGIBA, 2002, p.54). Sua natureza jurídica é esclarecida por Moreira (1999, p.65),

[...] são órgãos concebidos para influir constitutivamente na vontade normativa do Estado, mediante o exercício de competências conferidas pelas respectivas leis criadoras, que devem trazer as linhas definidoras de seu campo de atuação. [...] constituem-se em instâncias de caráter deliberativo, porém não executivo; são órgãos com função de controle, contudo não correicional das políticas sociais, à base de anulação do poder político. O Conselho não quebra o monopólio estatal

\footnotetext{
${ }^{4}$ Levantamento do IPEA aponta que do início da década de 1990 até 2010 haviam sido criados 26 Conselhos Nacionais com vistas a promover a interação do Estado com a sociedade no planejamento, formulação e controle de políticas públicas. No nível local, observou-se a criação de mais de 1500 Conselhos municipais de políticas públicas entre os anos de 2001 e 2009 (IPEA, 2010).

${ }^{5}$ Para maiores esclarecimentos sobre a descentralização das políticas sociais no Brasil ver ARRETCHE, Marta. 1999.
} 
da produção do Direito, mas pode obrigar o Estado a elaborar normas de Direito de forma compartilhada [...] em co-gestão com a sociedade civil.

Ou seja, a perspectiva é de que os Conselhos se constituam em fóruns que integram a sociedade civil ao processo decisório e que possuam capacidade de influenciar as políticas públicas. Devem servir como espaço público de deliberação, assegurando a livre defesa e expressão de opiniões por parte dos conselheiros que o compõem. Por este motivo, estas instituições mitigariam os efeitos negativos da democracia representativa, afastando as decisões baseadas em acordos clientelistas.

Apesar disso, estudos vêm demonstrando dificuldades dos Conselhos em garantir a participação social (TATAGIBA, 2002; NOGUEIRA, 2005; CÔRTES, 2007). O Estado ainda aparece como protagonista na definição e priorização das políticas públicas. Mesmo percebendo a criação destes espaços como condição para o controle social, sua existência não é suficiente para garantir que os participantes atuem de fato no processo decisório.

Vaz (2011) enumera três frentes de estudos sobre os Conselhos: (1) pesquisas sobre o caráter deliberativo dos conselhos; (2) trabalhos preocupado com o desenho institucional dos conselhos; e (3) estudos sobre a representatividade dos conselheiros. Dentre estes, as pesquisas sobre os arranjos institucionais apresentam importantes contribuições para compreensão das formas de funcionamento destes canais participativos. Estes trabalhos partem da premissa de que as normas induzem ou constrangem determinados comportamentos por parte dos participantes. Assim, a análise institucional seria um importante meio de verificar a presença ou não dos princípios que serviram de base para criação e funcionamento dos Conselhos.

Buscando demonstrar como as variáveis institucionais podem influenciar nas dinâmicas participativas, deliberativas e representativas dos fóruns participativos, Faria e Ribeiro (2011) colocam que o desenho institucional é aspecto determinante para efetividade dos Conselhos. Segundo as autoras,

os desenhos não são neutros, suas escolhas e variações incidem diretamente nessa
atuação [dos participantes], produzindo, assim, uma série de consequências para
os resultados da participação. [...] o desenho escolhido pode incidir: $\imath$ ) no caráter
da participação em termos de quantidade, vieses e qualidade da deliberação; ii) na
capacidade de informar os representantes, os cidadãos e de fomentar as
habilidades da cidadania; iii) na relação com o Estado em termos de controle
público, justiça das políticas e sua eficácia; bem como iv) na capacidade de
mobilização popular (FARIA e RIBEIRO, 2011, p. 127).

Percebe-se, assim, que os parâmetros que regem o funcionamento dos Conselhos constituem dimensão central para se verificar o cumprimento das atribuições funcionais 
destas instituições participativas. Dentre os aspectos que devem ser considerados pelos estudos sobre o arranjo institucional destaca-se o grau de institucionalização dos Conselhos. Sua mensuração passa pela investigação de variáveis como: o tempo de existência dessas instituições; a existência de uma estrutura organizacional; e a frequência de reuniões obrigatórias (VAZ, 2011; FARIA e RIBEIRO, 2011).

Em pesquisa sobre os Conselhos municipais, Tatagiba (2002) identifica problemas na forma de funcionamento dessas instituições. A partir da análise de teses e dissertações sobre o tema, a autora busca instituir generalizações possíveis para compreensão destes fóruns de participação. Uma das falhas identificadas está na garantia de paridade dos Conselhos. Como sua principal atribuição é incluir a população no processo decisório, o equilíbrio de forças entre Estado e sociedade mostra-se essencial. A paridade ganha mais relevância quando se percebe que mesmo existindo, o Estado ainda consegue aparecer como protagonista nas decisões do Conselho.

A capacidade de deliberação é outro importante fator para eficácia destas instituições participativas. Segundo a autora, "a competência legal de deliberar sobre as políticas públicas é a principal força dos Conselhos enquanto espaços potencialmente capazes de induzir à reforma democrática do Estado" (TATAGIBA, 2002, p.55). Entretanto, as pesquisas vêm demonstrando que o debate em torno de ideias ou políticas são pouco recorrentes nas reuniões dos Conselhos. Os representantes da sociedade civil não conseguem explicitar e defender suas opiniões, bem como não reconhecem no diálogo o principal meio para tomada de decisão.

O poder normativo dos Conselhos aparece como outra característica fundamental na influência da ação governamental. A competência de instituir normativos, tais como resoluções, vinculam as ações do ente público às decisões tomadas no âmbito destes fóruns. A falta de clareza quanto ao lugar dos Conselhos nas estruturas administrativas do Estado eles aparecem enquanto instituição da estrutura governamental? Ou se constituem numa instância paralela? - acaba por onerar o poder vinculante de suas deliberações.

Apesar destes problemas, as análises sobre os Conselhos indicam que eles possuem maior eficácia em inibir a transgressão por parte do Estado através da fiscalização. $O$ controle social seria facilitado pela existência de Fundos específicos, criados para que a 
gestão dos recursos passasse pelo Conselho. Tal formatação ampliaria a transparência dos gastos públicos, assim como facilitaria o monitoramento das iniciativas governamentais. Decorre deste ponto, a principal conclusão de Tatagiba (2002). Segundo ela, os Conselhos municipais vêm demonstrando "baixa capacidade propositiva". Deste modo, estas instituições possuiriam diminuto poder de influenciar as políticas públicas, o que reduziria seu potencial democratizante.

Para Nogueira (2005, p.141),

\begin{abstract}
Os conselhos, com os quais se imaginava aperfeiçoar a gestão das políticas descentralizadas, em poucos casos funcionavam, cortados por descontinuidades e bloqueios variados. As formas e os ritmos da descentralização variaram muito, assim como variou bastante o modo como ela foi implantada e funcionou em cada região do país e em cada área das políticas sociais. Não se pode concluir, portanto, que se tratou de uma política bem-sucedida.
\end{abstract}

Por não apresentar evidências empíricas que comprovem a completa ineficácia dos Conselhos, o discurso do autor soa generalista. No entanto, é notório que a introdução destes espaços às estruturas da gestão pública brasileira seguiu o desenvolvimento institucional de cada área de política pública. Além disso, o momento de sua criação e seu modo de funcionamento possuem especificidades inerentes a cada estado e/ou município.

Parece haver uma heterogeneidade quanto a capacidade dos Conselhos em influenciar os negócios públicos, que se expressa tanto pelo setor da política pública quanto pela sua esfera de atuação. Analisar as características e a estrutura de funcionamento destas instituições participativas constitui-se num importante meio para avaliar e compreender o potencial democratizante destes espaços institucionalizados de participação.

\title{
3. CONSTRUINDO O ÍNDICE DE CAPACIDADE INSTITUCIONAL DOS CONSELHOS (ICI)
}

São poucos os estudos que se propuseram a construir um indicador que possibilitasse a averiguação do funcionamento dos Conselhos de políticas públicas no Brasil. Em sua dissertação de mestrado, Silvia Toledo (2005), com base na MUNIC (Pesquisa de Informações Básicas Municipais do IBGE), propôs o Índice de Estrutura de Participação (IEP). Seu objetivo foi definir um dado que agregasse a existência e as condições de funcionamento dos Conselhos Municipais vinculados à gestão urbana dos municípios. O IEP seria "uma medida das condições institucionais de que o município dispõe para 
participação qualificada da sociedade no processo de gestão urbana municipal” (TOLEDO, 2005, p.69).

O IEP se utiliza de três variáveis: existência do conselho, caráter paritário e realização de reuniões. Mostra-se, dessa forma, insuficiente para indicar as condições institucionais para efetivação da participação social nos processos decisórios. Como já colocado, outros fatores são essenciais para que os Conselhos cumpram com sua função democratizante, como é o caso do caráter deliberativo, fiscalizador, normativo, etc.

O desafio, então, é construir um indicador que permita mensurar a capacidade institucional dos Conselhos de Políticas Públicas, deixando claro suas limitações e possibilidades de utilização. Para tanto, convém esclarecer que o termo capacidade envolve uma perspectiva de ação potencial, que induz a uma "possibilidade" de efetivação sua função institucional. Neste sentido, o ICI, antes de se insurgir enquanto indicador que quantifica o poder de influência dos Conselhos na agenda governamental e na promoção de políticas públicas, aufere significância pelo seu potencial de questionar a efetividade destes espaços de participação. Ou seja, elevados níveis de capacidade institucional não garantem que o Conselho afete a atuação estatal, no entanto, baixos índices tendem a comprovar sua ineficácia funcional.

As variáveis componentes do ICI foram definidas com base nos estudos sobre os Conselhos de políticas públicas, sobretudo, no trabalho de Tatagiba (2002), bem como na Pesquisa de Informações Básicas Estaduais (ESTADIC) do IBGE, são elas: existência do conselho, paridade, caráter deliberativo, caráter normativo, caráter fiscalizador, realização de reunião nos últimos 12 meses e existência de fundos específicos.

A ESTADIC trata-se de uma nova pesquisa do IBGE, publicada em 2013, cujo informante era a autoridade do executivo estadual, secretário de estado ou outro representante devidamente indicado pelo gestor para o fornecimento das informações. A coleta de dados foi realizada através de dois questionários - Questionário Básico e Suplemento de Assistência Social. O Questionário Básico coletou informações da gestão e equipamentos estaduais, dados sobre recursos humanos, existência de Conselhos, suas características e respectivos fundos, política de gênero, direitos humanos, segurança 
alimentar e nutricional e inclusão produtiva. No suplemento sobre Assistência Social foram coletadas informações mais detalhadas sobre a estrutura de gestão deste setor.

Para a pesquisa do IBGE, o Conselho foi considerado como instrumento de fortalecimento da participação democrática da população na formulação e implementação de políticas públicas. Em relação às características, a pesquisa utilizou os seguintes conceitos: conselho deliberativo refere-se àquele que efetivamente tem poder de decidir sobre a implantação de políticas e/ou a administração de recursos relativos à sua área de atuação; conselho fiscalizador é o que fiscaliza a implementação e o funcionamento de políticas e/ou a administração de recursos relativos à sua área de atuação; conselho normativo estabelece normas e diretrizes para as políticas e/ou a administração de recursos relativos à sua área de atuação; e conselho paritário apresenta um número igual de representantes da sociedade civil e do setor governamental.

Nesta perspectiva, a construção de um indicador para mensurar a capacidade institucional dos conselhos de políticas públicas contribuirá para compreensão do funcionamento destas instituições no nível estadual, permitindo a atuação estatal no seu aperfeiçoamento. Poderá ainda, fornecer subsídios para os movimentos sociais e a sociedade civil acompanharem o desenvolvimento institucional destes espaços, pressionando o Estado para efetivação da democratização do processo decisório. Tal instrumento reveste-se de maior importância para União, tendo em vista seu importante papel coordenativo e indutor.

Como colocado, o IEP foi construído com base em informações disponíveis para os governos municipais, no entanto, a proposta ora apresentada propôs construir um índice correlato para os Estados, a partir dos dados da ESTADIC que disponibiliza as mesmas variáveis nesse nível governamental, mas ampliando e incluindo na medida, para os conselhos estaduais, as características: existência do conselho, caráter paritário, deliberativo, normativo, fiscalizador, ocorrência de reunião nos últimos doze meses e existência de fundo específico para a área de política pública.

O ICI refere-se à relação entre o somatório das características dos conselhos $(\mathrm{P})$ que compõe o numerador e o somatório das características estudadas (T) que compõe o denominador. Para o cálculo do ICI, foi considerado que para cada característica presente era atribuído "1" (um) ponto e para a ausência da mesma era atribuído "0" (zero) ponto. No 
caso do denominador, considerando que eram 7 (sete) as características estudadas dos conselhos, o valor de $\mathrm{T}$ foi fixado neste nível.

Para cálculo do índice foi aplicada a seguinte fórmula:

$$
\mathrm{ICI}_{\mathrm{x}}=\underline{\boldsymbol{\Sigma}(\mathbf{P})}
$$

$\Sigma \mathrm{T}$

Onde:

$\mathbf{P}=(\mathrm{E}+\mathrm{P}+\mathrm{D}+\mathrm{N}+$ Fis $+\mathrm{R}+\mathrm{Fun})$

$\mathbf{T}=7$

$\mathrm{x}=$ nacional, por região ou por área de política pública.

$\mathrm{P}=$ Existência do Conselho, existência de fundos, realização de reunião nos últimos 12 meses e características presentes nos Conselhos existentes (paritário, deliberativo e normativo), nacionalmente, por cada região e por área de política pública, investigados pela ESTADIC. Para cada uma dessas variáveis foi atribuído o valor " 1 " e para as ausentes foi atribuído o valor " 0 ".

$\mathrm{T}=$ Total das variáveis, considerando o total nacional, por cada região e por política pública.

Para Brasil:

$$
\mathrm{ICI}_{\text {Brasil }}=\underline{\boldsymbol{\Sigma}(\mathbf{P})}
$$

$\Sigma T$

Por região:

$$
\mathrm{ICI}_{\text {Região }}=\underline{\boldsymbol{\Sigma}(\mathbf{P})}
$$

$\Sigma T$

Por área:

$$
\mathrm{ICI}_{\text {Área }}=\underline{\boldsymbol{\Sigma}(\mathbf{P})}
$$


O valor do ICI varia de 0 a 1 , sendo os valores próximos a " 0 " representantes de capacidade institucional frágil e os valores próximos a " 1 " indicadores de forte capacidade institucional.

\section{A CAPACIDADE INSTITUCIONAL DS CONSELHOS ESTADUAIS DE POLÍTICAS PÚBLICAS (ICI)}

Para aplicação do ICI nos Conselhos estaduais foram escolhidas nove áreas de atuação governamental cuja Constituição de 1988 compartilha as responsabilidades entre os três entes federados, a saber: educação, cultura, esporte, habitação, transporte, saúde, segurança pública, meio ambiente e assistência social. A escolha apenas foi possível pela disponibilização das informações pela ESTADIC sobre os conselhos destas áreas.

O quadro abaixo apresenta os resultados encontrados no cálculo do ICI.

Quadro 1 - Índice de Capacidade Institucional dos Conselhos Estaduais, por unidade geográfica, global e por área de política pública.

\begin{tabular}{|c|c|c|c|c|c|c|c|c|c|c|}
\hline $\begin{array}{l}\text { Unidade } \\
\text { Geográfica }\end{array}$ & $\begin{array}{c}\text { ICI } \\
\text { Glob } \\
\text { al }\end{array}$ & $\begin{array}{c}\text { Edu } \\
\text { caçã } \\
\text { o }\end{array}$ & $\begin{array}{c}\text { Cultur } \\
\mathbf{a}\end{array}$ & $\begin{array}{c}\text { Espor } \\
\text { te }\end{array}$ & $\begin{array}{c}\text { Habit } \\
\text { ação }\end{array}$ & $\begin{array}{l}\text { Trans } \\
\text { porte }\end{array}$ & $\begin{array}{l}\text { Saúd } \\
\text { e }\end{array}$ & $\begin{array}{l}\text { Seg. } \\
\text { Públi } \\
\text { ca }\end{array}$ & $\begin{array}{c}\text { Meio } \\
\text { Ambi } \\
\text { ente }\end{array}$ & $\begin{array}{l}\text { Ass. } \\
\text { Social }\end{array}$ \\
\hline BRASIL & 0,63 & 0,82 & 0,76 & 0,46 & 0,50 & 0,29 & 0,86 & 0,35 & 0,82 & 0,82 \\
\hline NORTE & 0,60 & 0,82 & 0,80 & 0,22 & 0,31 & 0,18 & 0,90 & 0,45 & 0,92 & 0,82 \\
\hline Rondônia & 0,56 & 1,00 & 0,71 & 0,43 & 0,00 & 0,00 & 1,00 & 0,00 & 1,00 & 0,86 \\
\hline Acre & 0,62 & 0,71 & 1,00 & 0,00 & 0,71 & 0,00 & 0,86 & 0,57 & 0,86 & 0,86 \\
\hline Amazonas & 0,62 & 0,86 & 0,86 & 0,57 & 0,14 & 0,00 & 0,86 & 0,57 & 0,86 & 0,86 \\
\hline Roraima & 0,48 & 0,71 & 0,71 & 0,00 & 0,14 & 0,14 & 1,00 & 0,00 & 0,71 & 0,86 \\
\hline Pará & 0,73 & 0,86 & 0,71 & 0,57 & 0,14 & 0,71 & 0,71 & 1,00 & 1,00 & 0,86 \\
\hline Amapá & 0,51 & 0,86 & 0,86 & 0,00 & 0,00 & 0,00 & 1,00 & 0,00 & 1,00 & 0,86 \\
\hline Tocantins & 0,70 & 0,71 & 0,71 & 0,00 & 1,00 & 0,43 & 0,86 & 1,00 & 1,00 & 0,57 \\
\hline $\begin{array}{c}\text { NORDES } \\
\text { TE }\end{array}$ & 0,61 & 0,84 & 0,73 & 0,48 & 0,52 & 0,00 & 0,87 & 0,40 & 0,81 & 0,81 \\
\hline Maranhão & 0,62 & 0,71 & 1,00 & 0,29 & 0,71 & 0,00 & 0,86 & 0,71 & 0,57 & 0,71 \\
\hline Piauí & 0,48 & 0,57 & 0,29 & 0,57 & 0,57 & 0,00 & 0,71 & 0,00 & 0,71 & 0,86 \\
\hline
\end{tabular}


SILVA, André Luis Nogueira da \& SOUZA, Damião Ernane de. Mensurando a democracia nos governos estaduais: uma proposta para construção do Índice de Capacidade Institucional dos Conselhos de Políticas Públicas (ICI)

\begin{tabular}{|c|c|c|c|c|c|c|c|c|c|c|}
\hline Ceará & 0,78 & 0,86 & 0,71 & 1,00 & 0,71 & 0,00 & 1,00 & 0,86 & 1,00 & 0,86 \\
\hline $\begin{array}{l}\text { R. G. do } \\
\text { Norte }\end{array}$ & 0,56 & 0,86 & 0,86 & 0,71 & 0,00 & 0,00 & 0,86 & 0,00 & 0,86 & 0,86 \\
\hline Paraíba & 0,62 & 0,86 & 1,00 & 0,14 & 0,71 & 0,00 & 0,71 & 0,43 & 0,86 & 0,86 \\
\hline $\begin{array}{c}\text { Pernambuc } \\
\text { o }\end{array}$ & 0,71 & 0,86 & 0,57 & 1,00 & 0,71 & 0,00 & 0,86 & 0,86 & 0,71 & 0,86 \\
\hline Alagoas & 0,67 & 1,00 & 0,57 & 0,57 & 0,57 & 0,00 & 1,00 & 0,71 & 0,86 & 0,71 \\
\hline Sergipe & 0,46 & 0,86 & 0,86 & 0,00 & 0,00 & 0,00 & 0,86 & 0,00 & 0,86 & 0,71 \\
\hline Bahia & 0,57 & 1,00 & 0,71 & 0,00 & 0,71 & 0,00 & 1,00 & 0,00 & 0,86 & 0,86 \\
\hline SUDESTE & 0,54 & 0,79 & 0,54 & 0,36 & 0,61 & 0,32 & 0,75 & 0,04 & 0,68 & 0,75 \\
\hline $\begin{array}{l}\text { Minas } \\
\text { Gerais }\end{array}$ & 0,67 & 1,00 & 0,71 & 0,57 & 0,57 & 0,71 & 0,71 & 0,00 & 0,86 & 0,86 \\
\hline $\begin{array}{c}\text { Espírito } \\
\text { Santo }\end{array}$ & 0,51 & 0,86 & 0,57 & 0,00 & 0,86 & 0,00 & 1,00 & 0,00 & 0,71 & 0,57 \\
\hline $\begin{array}{c}\text { R. de } \\
\text { Janeiro }\end{array}$ & 0,41 & 0,43 & 0,29 & 0,14 & 0,43 & 0,29 & 0,57 & 0,14 & 0,57 & 0,86 \\
\hline São Paulo & 0,56 & 0,86 & 0,57 & 0,71 & 0,57 & 0,29 & 0,71 & 0,00 & 0,57 & 0,71 \\
\hline SUL & 0,68 & 0,71 & 0,86 & 0,76 & 0,48 & 0,43 & 0,95 & 0,24 & 0,86 & 0,86 \\
\hline Paraná & 0,71 & 0,57 & 1,00 & 0,86 & 0,86 & 0,00 & 1,00 & 0,43 & 0,86 & 0,86 \\
\hline S. Catarina & 0,67 & 0,71 & 0,71 & 0,71 & 0,00 & 1,00 & 0,86 & 0,29 & 0,86 & 0,86 \\
\hline R. G. do Sul & 0,67 & 0,86 & 0,86 & 0,71 & 0,57 & 0,29 & 1,00 & 0,00 & 0,86 & 0,86 \\
\hline $\begin{array}{c}\text { CENTRO- } \\
\text { OESTE }\end{array}$ & 0,72 & 0,93 & 0,89 & 0,46 & 0,57 & 0,50 & 0,82 & 0,64 & 0,82 & 0,86 \\
\hline $\begin{array}{c}\text { Mato } \\
\text { Grosso do } \\
\text { Sul }\end{array}$ & 0,60 & 0,86 & 0,71 & 0,14 & 0,71 & 0,57 & 0,57 & 0,43 & 0,57 & 0,86 \\
\hline $\begin{array}{c}\text { Mato } \\
\text { Grosso }\end{array}$ & 0,89 & 1,00 & 1,00 & 1,00 & 0,86 & 0,57 & 0,86 & 1,00 & 0,86 & 0,86 \\
\hline Goiás & 0,59 & 0,86 & 0,86 & 0,00 & 0,14 & 0,14 & 0,86 & 0,71 & 0,86 & 0,86 \\
\hline $\begin{array}{l}\text { Distrito } \\
\text { Federal }\end{array}$ & 0,81 & 1,00 & 1,00 & 0,71 & 0,57 & 0,71 & 1,00 & 0,43 & 1,00 & 0,86 \\
\hline
\end{tabular}

Fonte: Elaborado pelos autores a partir dos dados da Pesquisa de Informações Básicas Estaduais do IBGE de 2012. 
A constituição do ICI global nos estados se deu a partir da média obtida dos ICIs de todas áreas de atuação governamental analisadas. Este indicador constrói um retrato da situação geral dos conselhos estaduais em cada unidade federativa, favorecendo uma análise, mesmo que superficial, da permeabilidade deste nível de governo às demandas da sociedade. Podem sugerir, assim, o papel que os conselhos assumem na estrutura decisória dos governos estaduais. Ou seja, indicam se o funcionamento dos conselhos compõe o projeto político do executivo estadual. Observou-se que 16 estados possuem ICI global abaixo do índice registrado para o Brasil $(0,63)$ - o mesmo que a média nacional. Rio de Janeiro $(0,41)$, Sergipe $(0,46)$, Piauí $(0,48)$ e Roraíma $(0,48)$ apresentaram os escores mais baixos, enquanto Mato Grosso $(0,89)$ e o Distrito Federal $(0,81)$ registraram os maiores índices.

Percebe-se, ainda, uma heterogeneidade inter e intraregional, o que sugere que a posição geográfica não é determinante na definição da capacidade de atuação dos conselhos. Apesar disso, é importante observar a reduzida discrepância do ICI global registrado para os estados do Sul. Seus índices, ademais, superam a média nacional. Não há, assim, qualquer padrão regional de capacidade institucional dos conselhos, havendo uma heterogeneidade dentro das 05 (cinco) regiões do país. Outra questão perceptível é que o nível econômico do estado também não é variável explicativa no que ser refere a importância dos conselhos no processo decisório estadual. ICI global do Pará, por exemplo, é bem superior ao que fora encontrado em São Paulo.

$\mathrm{Na}$ avaliação por área de política pública, nacionalmente, a área de Saúde destaca-se como aquela de maior capacidade institucional, apresentando um ICI de 0,86, seguida das áreas de Educação, Meio Ambiente e Assistência Social com ICI de 0,82. A área de cultura também registrou um bom escore $(0,76)$, tendo um potencial de ampliação, vez que apresentou existência de conselho em todos os estados. Todos estes setores estão organizados em sistemas nacionais de políticas públicas, cuja constituição fora coordenada e implementada pelo governo central ${ }^{6}$. Esta situação sugere que o desenvolvimento institucional de políticas nacionais é variável exógena a ser considerada nas análises sobre a efetividade dos conselhos de políticas públicas.

Os conselhos estaduais nas áreas de transporte, segurança pública, esporte e habitação apresentaram baixos ICIs. Em todos estes setores, o ICI ficou igual ou abaixo de

6 Sistema Único de Saúde (1990), Sistema Único de Assistência Social (2005), Sistema Nacional de Educação (2009), Sistema Nacional de Cultura (2010). 
0,5, o que indica para uma quase completa ineficácia funcional dos conselhos. Convém colocar que muitos estados sequer possuem conselhos implantados nestes setores. Dentre eles, convém destacar a área de transportes que apresentou o pior ICI $(0,29)$. Tal setor é de extrema relevância para os governos estaduais, tendo em vista que a metropolização é um processo cada vez mais presente nas grandes cidades brasileiras. Há, assim, a maximização da necessidade de integração do transporte coletivo entre os municípios de uma região metropolitana. A coordenação destas ações é de competência dos estados, que demonstra carência de um fórum participativo capaz de influenciar as iniciativas governamentais.

Outra área com frágil capacidade institucional dos conselhos estaduais é a segurança pública. Com atribuições constitucionais concentradas nos governos estaduais - responsável pela atuação da polícia judiciária (civil) e ostensiva (militar) - este setor registrou o segundo pior escore $(0,35)$. Tal cenário demonstra uma dificuldade do executivo estadual em promover a democratização do processo decisório no âmbito das suas ações de segurança pública.

As políticas estaduais voltadas ao esporte $(0,46)$ e habitação $(0,50)$ também parecem conviver com a falta de discussão pública e de democratização de suas decisões. A ausência de conselhos ou mesmo de características primárias para que eles atuem conforme premissas deliberativas demonstram gestões estaduais pouco permeáveis a participação social.

\section{CONSIDERAÇÕES FINAIS}

Os resultados encontrados na aplicação do ICI para os conselhos estaduais sugerem a ineficácia funcional destes espaços institucionalizados de participação, o que converge com proposições de pesquisas anteriores (TATAGIBA, 2002; NOGUEIRA, 2005; SILVA e SOUZA, 2013). Por outro lado, apontam para uma heterogeneidade no nível de capacidade institucional dos conselhos, observada nas regiões e por área de políticas pública.

Como já dito, a relevância do ICI está na sua aptidão em questionar a efetividade dos conselhos, pois sua existência, realização de reuniões periódicas, detenção de fundo específico e de caráter paritário, deliberativo, fiscalizador e normativo não garantem sua influência nas decisões governamentais, no entanto, a ausência destas características/variáveis impede a plenitude de sua função política. 
Nesta perspectiva, as regiões sudeste, norte e nordeste apresentaram os piores ICI's de seus conselhos estaduais, demonstrando que a posição geográfica e o feitio econômico do estado não possuem relação com a capacidade institucional destes espaços de participação. Não obstante, as áreas de transporte, segurança pública, esporte e habitação apresentaram ICI's extremamente baixos, sugerindo uma incapacidade institucional de seus conselhos estaduais e assim, ausência de participação social em seus processos decisórios.

Deste modo, funcionamento parcial dos conselhos de políticas públicas ainda constitui-se num empecilho para a democratização do processo decisório no âmbito estadual. Devido ao seu protagonismo coordenativo e sua potencialidade indutora, a União tem um papel fundamental para aprimorar estes canais de participação popular. Prova disso é a alta capacidade institucional de conselhos de áreas com intensa influência do ente federal, como saúde, educação e assistência social - organizadas a partir de sistemas nacionais de políticas públicas.

Tal proposição sugere uma reduzida propensão dos gestores estaduais em democratizar o processo decisório em áreas pouco reguladas pelo governo central. Aponta, ademais, para a necessidade dos estudos sobre instituições participativas incluírem o desenho institucional da sua área de atuação como variável relevante para a mensuração de sua efetividade.

\section{REFERÊNCIAS}

ARRETCHE, M. Políticas sociais no Brasil: descentralização em um estado federativo. Revista Brasileira de Ciências Sociais, vol. 14, n.14, jun.1999. p.111-141

AVRITZER. L. A qualidade da democracia e a questão da efetividade da participação: mapeando o debate. In: PIRES, Roberto Rocha C. (Org.). Efetividade das Instituições participativas no Brasil: estratégias de avaliação. Brasília: Ipea, 2011. p. 13-25.

BABBIE, E. Métodos de Pesquisa Survey. Belo Horizonte: UFMG, 1987.

Brasil em Desenvolvimento: Estado, planejamento e políticas públicas / Instituto de Pesquisa Econômica Aplicada. Instituições Participativas e Políticas Públicas no Brasil: Características e Evolução nas Últimas Duas Décadas. Brasília: Ipea, 2010, 270 p. 3 v.

BELLEN, H. M. V. Indicadores de sustentabilidade: uma análise comparativa. Rio de Janeiro: FGV, 2005, p 41-80. 
CORTES, S. V. Viabilizando a Participação em Conselhos de Política Pública Municipais: arcabouço institucional, organização do movimento popular e policy communities. IN: HOCHMAN, Gilberto; ARRETCHE, Marta; MARQUES, Eduardo (Orgs.). Políticas Públicas no Brasil. Rio de Janeiro: FIOCRUZ, 2007.

CUNHA, E. S. M.; ALMEIDA, D. C. R. de; FARIA, C. F.; RIBEIRO, U. C. Uma estratégia multidimensional de avaliação dos conselhos de políticas: dinâmica deliberativa, desenho institucional e fatores exógenos. In: PIRES, Roberto Rocha C. (Org.). Efetividade das Instituições participativas no Brasil: estratégias de avaliação. Brasília: Ipea, 2011. Cap.20.p.297-321.

CUNHA, E. S. M. O potencial de conselhos de políticas e Orçamentos Participativos para o aprofundamento democrático. IN: DAGNINO, Evelina; TATAGIBA, Luciana (Orgs.). Democracia, Sociedade Civil e Participação. Chapecó: Argos, 2007.

DAGNINO, E. (Org.). Sociedade civil e espaços públicos no Brasil. IN: Sociedade Civil e Espaços Públicos no Brasil. São Paulo: Paz e Terra, 2002.

DAHL, R. A. A Democracia e seus críticos. Trad. Patricia de Freitas Ribeiro. São Paulo: WMF Martins Fontes, 2012.

GOHN, M. da G. Emponderamento e participação da comunidade em políticas sociais. Saúde e Sociedade. v.13, n.2, maio-ago, 2004, p.20-31.

IBGE. Pesquisa de Informações Básicas Estaduais (ESTADIC), 2012. Disponível em <http://www.ibge.gov.br/home/estatistica/economia/estadic/estadic2013/default.shtm> Acesso em 01.nov.2014.

JANNUZZI, P. de M. (I)ndicadores Sociais no Brasil. Campinas: Alínea, 2012.

MOREIRA, M. T. V. Instâncias deliberativas dos sistemas descentralizados e participativos das políticas públicas de cunho social: contorno jurídico dos conselhos. IN: INFORMATIVO CEPAM. São Paulo: Fundação Prefeito Faria Lima, 1999.

NOGUEIRA, M. A. Um Estado para a sociedade civil: temas éticos e políticos da gestão democrática. 2.ed. São Paulo: Cortez, 2005.

SANTAGADA, S. Indicadores Sociais: uma primeira abordagem social histórica. Pensamento Plural. 1:113-142, 2007.

SILVA, A. L. N. da; SOUZA, D. E. de. Deliberação e controle social: um perfil dos conselhos estaduais de políticas públicas no nordeste brasileiro. Revista Eletrônica de Ciência Política, vol. 4, n. 1-2, 2013.

TATAGIBA, L. Os Conselhos Gestores e a Democratização das Políticas Públicas no Brasil. IN: DAGNINO, Evelina (Org.). Sociedade Civil e Espaços Públicos no Brasil. São Paulo: Paz e Terra, 2002. 
TOLEDO, S. Indicadores de capacidade de gestão ambiental urbana dos governos locais nas cidades médias do estado de São Paulo. Dissertação de mestrado, Universidade Estadual Paulista, 2005.

TUNSTALL, D. Developing and using indicators of sustainable development in Africa: an overview, doc mimeo. In: The Network for Environment and Sustainable Development in Africa (NESDA), Thematic Workshop On Indicators Of Sustainable Development. Banjul, Gambia: NESDA, 1994.

ULTRAMARI, C. Indicadores analíticos: um recurso de gestão e planejamento. IN: KEINERT, Tania; KARRUZ, Ana Paula (orgs). Qualidade de vida: observatórios, experiências e metodologias. São Paulo: Amablume/FAPESP, 2002, p107-115.

VAZ, A. C. N. Da participação à qualidade da deliberação em fóruns públicos: o itinerário da literatura sobre conselhos no Brasil. In: PIRES, Roberto Rocha C. (Org.). Efetividade das Instituições participativas no Brasil: estratégias de avaliação. Brasília: Ipea, 2011. Cap.6. p. 91-108. 